Aus dem Kgl. Institut für Infektionskrankheiten „,Robert Koch“ (Direktor: Geh. Med.-Rat Prof. Neufeld) und der Infektionsabteilung des Rudolf-Virchow-Krankenhauses in Berlin.

\title{
Experimentelle Untersuchungen über die Uebertragung der Pocken.
}

Von Prof. Dr. Ulrich Friedemann und Dr. H. A. Gins.

Die Kenntnisse von der Uebertragung des Variolavirus, insbesondere von der Ausscheidung, den Verbreitungswegen und den Eintrittspforten des Pockenerregers, sind bisher weniger auf experimentelle Tatsachen als auf epidemiologische Beobachtungen gegründet. Die Anschauungen entbehren daher vielfach einer streng beweisenden Grundlage und zeigen keine Einheitlichkeit. Dieser lückenhafte Zustand der Forschung auf einem klinisch seit langem besonders sorgfältig studierten Gebiet ist durch die Unvollkommenheiten der mikrobiologischen Technik gerade in dieser Frage begründet. Die Unkenntnis des Pockenerregers, die Unmöglichkeit, ihn außerhalb des menschlichen Körpers zu reproduzieren, haben die Anwendung jener Methoden bisher auf das Studium der Pocken verboten, die bei anderen. Infektionskrankheiten so vollkommene Ergebnisse erzielt haben.

Die letzten Dezennien haben nach dieser Richtung nicht unbedeutende Fortschritte, gebracht. Wenn auch über die Natur des Pockenerregers noch keine Sicherheit herrscht, so kennen wir doch seit den Arbeiten von L. Pfeitfer, van der Lo eff 'und Guarnieri in den von diesen Autoren beschriebenen und gegenwärtig allgemein als Guarnierische Körperchen bezeichneten Elementen Gebilde, die für den Pockenprozeß spezifisch sind und die Anwesenheit des Pockenerregers mit Sicherheit beweisen.

Noch wichtiger aber für die anfangs bezeichnete Fragestellung ist die Tatsache, daß es gelungen ist, den Pockenerreger außerhalb des menschlichen Körpers zu reproduzieren. Guarnieri impfte Variola- und Vakzinevirus in die Hornhaut des Kaninchens und beobachtete charakteristische Veränderungen, in denen er mikroskopisch die spezifischen Körperchen nachweisen konnte. Wasielewski und Jürgens haben dieses Verfahren für die Diagnose der Pocken praktisch verwertet. Durch eine Aenderung der Technik hat dann $\mathrm{Pa}$ ul diese Methode so verbessert, daß sie gegenwärtig als eine sehr wertvolle $\mathrm{Be}$ reicherung unserer diagnostischen Hilfsmittel auf dem Gebiet der Pockenerkrankungen betrachtet werden muß. ${ }^{1}$ )

Ueber die Tuchnik und die Ergebnisse ist dort bereits berichtet. Nachzutragen ist roch, $\mathrm{daB}$ die Aussichten für einen positiven Tierversuch sich augenscheinlich verbessern lassen, wenn der Pustelinhalt nicht ausgestrichen, sondern in Gestalt dicker Tropfen eingeschickt (Ungermann) und wenn der Pustelinhalt möglichst frühzeitig entnommen wird.

Jedenfalls aber ist zu wiederholen, daß bei klinischem Pockenverdacht der negative Paulsche Tierversuch nicht für die Diagnose entscheidend sein soll.

Von großer Bedeutung auch in theoretischer Hinsicht sind jene seltenen Fälle, bei denen wir einen positiven Paulschen Versuch feststellen und nachträglich erfahren, daß Pocken überhaupt nicht in Frage kommen. Für alle solche Fälle ist zu betonen, daß ein stark positiver Versuch niemals in Frage kam, sondern daß die positive Diagnose immer auf vereinzelte Herde in der Hornhaut gegründet war. Unter den letzten 1000 Diagnosen des Pockenlaboratoriums finden sich sechs Fälle von Windpocken mit positivem Tierversuch. Wenn sich unter diesen wohl noch einer findet, der zu Unrecht als Windpocken angesehen wurde, so bleibt die Tatsache doch bestehen, daß wir verschiedentlich irregeführt wurden. Weiterhin haben wir schwach positive Tierversuche gefunden bei einem Fall von Bromakne, bei einem Fall

1) Siehe 1916 Nr. 29 S. 900. 
von Impetigo contagiosa und bei vier Fällen luetischer Exantheme. Zumal die letzteren haben Schwierigkeiten gemacht, da zuerst Pockenverdacht geäußert war und die Möglichkeit einer Aufnahme von Pockenvirus nicht ausgeschlossen werden konnte. Der weitere Verlauf sicherte aber die Diagnose Lues. Diesen vier von uns als positiv bezeichneten Fällen stehen nun 12 Verimpfungen luetischen Materials mit völlig negativem Ergebnis gegenüber. Unter diesen finden sich zwei Primäraffekte, von denen uns Material durch Herrn Professor Wechselmann zur Verfügung gestellt wurde. Für die Ueberlassung dieses Materials sagen wir auch hier unsern verbindlichsten Dank. In beiden Primäraffekten wurde unmittelbar vor der Verimpfung die Spirochaete pallida nachgewiesen. Trotzdem also die Vorbedingungen für die Ansiedlung des luetischen Virus besonders günstig waren, kam keine positive Reaktion nach Paul zustande.

Wenn es bisher auch nicht gelang, diese Fehldiagnosen aufzuklären, so ist anderseits doch zu betonen, daß ihnen eine große praktische Bedeutung nicht zukommt. Selbst wenn bei je 100 Pockenverdächtigen einer fälschlich als Pockenkranker angesehen wird, kann hierdurch kein Schaden entstehen. Die medizinalpolizeiliche Bedeutung des Tierversuchs nach $\mathrm{Paul}$ wird durch diese Fehlermöglichkeiten nicht beeinträchtigt. Immerhin wird es notwendig sein, einzelne milchweiße Herde auf der Kornea mit einigem Mißtrauen zu betrachten und lieber eine unentschiedene Diagnose abzugeben, wenn nicht einwandfrei positiver Befund orhoben werden kann, besonders in denjenigen Fällen, in denen pustulöse Syphi]ide in Frage kommen können.

Die mikroskopische Untersuchung läßt leider in derartigen Fällen häufig im Stich, da es nicht regelmäßig gelingt, bei schwach positiven Fällen in den kleinen Papeln die Guarnierischen Körperchen in einer für die Diagnose ausreichenden Weise aufzufinden. Immerhin gelang es aoch, in mehreren der oben erwähnten Fälle durch die mikroskopische Untersuchung überzeugend nachzuweisen, daß Variola nicht in Frage kommen konnte.

Wir dürfen uns der Tatsache nicht verschließen, daß der Kaninchenhornhautversuch, so wertvoll er an sich ist, nicht die gleichen Vorzüge besitzt wie eine Züchtung des Virus auf künstlichem Nährboden. Die natürlichen Schutzkräfte der Gewebe setzen der Vermehrung des Erregers Abwehrkräfte entgegen, und deren Ueberwindung macht daher die Einimpfung größerer Mengen des Virus erforderlich, während auf künstlichem Nährboden unter günstigen Wachstumsbedingungen schon die geringste Zahl von Keimen zur schrankenlosen Vermehrung gebracht werden kann. Der Paulsche Versuch wird also voraussichtlich nur dort erfolgreich angewandt werden können, wo bereits eine Reproduktion des Virus stattgefunden hat, d. h. wenn das Material dem menschlichen Körper entnommen wird. Dagegen ist es nicht sehr wahrscheinlich, daß auch in der Umgebung des Menschen, in die das Virus gelangt, ohne sich aber dort vermehren zu können, das Kaninchenexperiment den Nachweis des Pockenerregers ermöglichen wird.

Trotz dieser Einschränkungen schien uns die Paulsche Methode geeignet, einige wichtige Fragen der Pockenepidemiologie in Angriff zu nehmen, und das reichliche Material der gehäuften Pockenfälle des Frühjahrs 1917 bot Gelegenheit, diese Versuche in größerem Maßstabe auszuführen.

Zwei Fragen haben wir einer experimentellen Prüfung unterzogen, nämlich

1. die Feststellung des Ausscheidungsweges des Virus beim pockenkranken Menschen,

2. das Vorkommen des Pockenvirus bei Rekonvaleszenten und Gesunden in der Umgebung Pockenkranker.

Wir teilen im folgenden zunächst unsere experimentellen Ergebnisse mit. Aus diesen wie aus klinischen und epidemiologischen Beobachtungen werden sich dann allgemeinere Anschauungen über den Infektionsweg bei der Variola ergeben.

Zur Verimpfung wurden möglichst frische Erkrankungen ausgewählt. Das Kaninchenauge war bereits vorher kokainisiert und gekratzt. Von der Schleimhautpustel wurde das Material mit dem Impfspatel abgekratzt und sofort auf das Kaninchenauge übertragen. Die Impfung mit noch feuchtem Material wurde gemacht, um den schädigenden Einfluß der Trocknung auszuschalten.

Es wurde von sechs verschiedenen Patienten Material entnommen, aus Schleimhautaffektionen der Wangen- oder Gaumenschleimhaut, die als typische Pocken anzusprechen waren. Fünfmal war die Verimpfung sehr stark erfolgreich, einmal konnte das Pocken virus nicht nachgewiesen werden.

Von vier dieser Patienten wurde gleichzeitig mit Hilfe eines Watte- tupfers Material von der Nasenschleimhaut abgestrichen und sofort verimpft. In allen vier Fällen war die Verimpfung stark erfolgreich, darunter auch in dem einen Fall, bei dem die Verimpfung des Gaumenschleimhaut materials negativ verlaufen war. Die Untersuchung der Nase mit dem Spiegel ließ bei mehreren Kranken sehr typische Pockenpusteln auf der Schleimhaut erkennen, sodaß das Ergebnis dieser Verimpfung nicht unerwartet kam.

Hatten die bisher erwähnten Kranken sichere Merkmale der Pockenerkrankung auf der Gaumenschleimhaut, so trifft dies nicht zu für zwei weitere Fälle, bei denen charakteristische Schleimhautveränderungen nicht vorhanden waren. Die Verimpfung des daher stammenden Materials blieb ergebnislos.

Um uns zul überzeugen, ob das Pockenvirus auf der unverletzten Schleimhaut über der Pockenpustel nachweisbar ist, wurde mit dem Wattebausch über unverletzte Schleimhautpusteln hinweggestrichen und dann das noch feuchte Material verimpft. Pockenvirus konnte in diesem Fall nicht nachgewiesen werden.

Ebenso scheint eine erhebliche Verbreitung des Virus in der Mund. höhle nicht vorhanden zu sein. Die Verimpfung des Speichels zweier Kranker mit reichlich befallener Schleimhaut blieb ergebnislos. Wir möchten aus diesen negativen Ergebnissen jedoch keine weitergehenden Schlïsse ziehen, da die Zahl unserer Untersuchungen nach dieser Richtung noch zu klein ist.

Ebenfalls ergebnislos war die Verimpfung von Abstrichen besprochener oder angehusteter Glasplatten. Da wir noch kein Mittel haben, das Pockenvirus zur Vermehrung zu bringen, sind uns die auf diese Weise zerstreuten, wenig zahlreichen und durch Antrocknung geschädigten Keime entgangen.

Von besonderem Interesse ist eine Versuchsreihe, die sich auf die Untersuchung von Gaumen- und Nasenschleimhaut Genesender bezieht. Bisher haben wir Material von $15 \mathrm{Ge}-$ nesenden untersucht. Der Abstrich von der Gaumenschleimhaut war immer negativ, was ja mit der mittlerweile erfolgten Abheilung der Schleimhauterkrankung gut übereinstimmt. Dagegen ergab die Verimpfung des Nasenabstriches in 2 von 15 Fällen ein positives Ergebnis.

In dem einen Fall war das Material vier Wochen nach der letzten Temperatursteigerung entnommen. Seine Verimpfung ergab auf der Kaninchenhornhaut wenige, aber charakteristische Papeln, sodaß der positive Tierversuch zweifelloswar. Der Nachweis der Guarnieri -Körperchen wurde in diesem Fall nicht angeschlossen.

Der andere Fall ist dadurch besonders wichtig, daß beim Beginn der Erkrankung das Pockenvirus nicht im Material einer Gaumenschleimhautpustel und nicht in der Hautpustel nachgewiesen wurde, sondern nur im Nasenabstrich. Und in diesem wurde es jetzt etwa drei Wochen nach Beginn der Rekonvaleszenz abermals nachgewiesen.

Die klinische Untersuchung der Nasenschleimhaut bei diesen beiden Kranken ergab:

Im ersten Fall waren acht Tage nach der Entnahme des Materials Veränderungen auf der Schleimhaut nicht mehr nachweisbar. Eine nochmalige Verimpfung von der Nasenschleimhaut auf die Kaninchenhornhaut ergab dann auch kein positives Resultat mehr.

Im zweiten Fall zeigten sich bei der einen Tag nach der Entnahme vorgenommenen Untersuchung deutliche Ulzera auf der Schleimhaut des rechten Nasenganges, während die linke Nasenhälfte anatomisch intakt war. Es wurden nun sofort von beiden Hälften gesonderte Abstriche gemacht und diese auf die Kaninchenhornhaut verimpft.

Uebereinstimmend mit dem klinischen Befund ergab nur die rechte Nasenhälfte ein positives Resultat.

Die Verimpfung der steril entnommenen und dann scharf zentrifugischen Urine von zwei Pockenkranken verlief negativ. Hieraus kann noch nicht geschlossen werden, daß die Ausscheidung des Virus durch die Nieren niemals stattfindet. Weitere Versuche nach dieser Richtung konnten bei der notwendigen Sparsamkeit mit dem Tiermaterial jetzt nicht ausgeführt werden.

Wir haben dann ferner von dem gesamten Pflegepersonal der Pockenstationen Abstriche von Mund- und Nasenschleimhaut gemacht. Alle diese 15 Personen betreffenden Untersuchungen verliefen negativ.

Ebensowenig konnten wir bei fünf Personen, die mehrere Tage in nächster Nähe einer Pockenpatientin gelegen hatten, Pockenvirus auf Mund. und Nasenschleimhaut nachweisen.

Unsere Versuche haben also zunächst die schon durch die Inokulation bekannte Tatsache bestätigt, daß das Variolavirus 
in der Pockenpustel lokalisiert ist. Es dürfte demnach kaum $\mathrm{zu}$ bezweifeln sein, wie dies ja auch mannigfache klinische Erfahrungen bestätigt haben, daß der Inhalt der Pockenpusteln, wenn er sich durch Platzen der Hautdecke nach außen entleert, infektiös ist.

Dieser Infektionsmodus kommt aber erst in den späteren Stadien der Erkrankung in Betracht.

Denn bei der Variola vera tritt eine Oeffnung der Pusteln sicherlich nicht vor dem achten Tage der Erkrankung ein. Vorher ist der Inhalt der Pustel durch eine außerordentlich derbe Epidermisschicht von der Außenwelt abgeschlossen, und es ist garnicht vorstellbar, daß das Virus durch diese hindurch seinen Weg in die Außenwelt finden sollte. Da trotzdem erwiesenermaßen die Pocken schon in den frühesten Stadien der Erkrankung hochgradig infektiös sind, so müssen also andere Ausscheidungswege im Beginn ausschlieBlich in Betracht kommen.

Die klinischen und pathologischen Beobachtungen weisen nun zusammen mit unseren experimentellen Ergebnissen mit großer Sicherheit darauf hin, daß die in den oberen Luftwegen, nämlich auf der Schleimhat der Nase, des Rachens, der Trachea und der Mundorgane (Zunge, Wangenschleimhaut) lokalisierten Krankheitsprozesse die wichtigsten Austrittspforten des Virus darstellen. Ob schon im Initialstadium diese Schleimhautveränderungen vorhanden sind, vermögen wir nicht mit Sicherheit zu sagen, da Kranke in diesem Stadium außerordentlich selten zur Beobachtung kommen. Dafür spricht vielleicht, daß die Kranken sehr häufig angeben, schon im Initialstadium Halsschmerzen und Schluckbeschwerden gehabt zu haben. Sicher ist aber, daß bereits ganz im Beginn des exanthematischen Stadiums, wenn sich die allerersten Zeichen des Exanthems auf der Haut zeigen, an den Schleimhäuten deutliche Veränderungen zu beobachten sind. Für die Verbreitung des Virus ist es ferner von größter Bedeutung, daß diese Schleimhauteffloreszenzen im Gegensatz zu den Hautpusteln sehr frühzeitig Neigung zum Zerfall zeigen. Mit diesen klinischen Beobachtungen stimmt es denn auch vollkommen überein, daß wir fast immer in diesen Schleimhautpusteln den Variolaerreger durch den. Tierversuch nachweisen konnten.

Wie wir uns regelmäßig bei Pockensektionen überzeugen konnten, beschränken sich die Schleimhautpusteln nicht auf die obersten Teile der Luftwege, sondern setzen sich auf die Schleimhaut der Trachea bis in die Verzweigungen der Bronchien fort. Diese Erkrankungen führen meist zu einem die Kranken sehr quälenden Husten. Es ist also nach den Ergebnissen unserer Versuche reichlich Gelegenheit gegeben, daß bei diesen Hustenstößen, aber auch beim Sprechen, auf demWege der Trö pfcheninfektion das Variolavirus in der den Kranken umgebenden Luft verteilt wird.

Wir erwähnten bereits im experimentellen Teil, daß wir die Tröpfchenverbreitung des Virus auch nach dem Vorbild der Flüggeschen Versuche durch Ansprechen und Anhusten von Glasplatten nachzuweisen suchten. Das negative Resultat dieser Versuche ist wohl auf die eingangs erörterten Mängel des Paulschen Verfahrens gegenüber der Züchtung des Virus auf künstlichem Nährboden zurückzuführen. Die geringen Mengen von Keimen, die auf diesem. Wege die Glasplatte erreichen und noch dazu durch Eintrocknung geschädigt werden, genügen wohl, um den sehr empfänglichen Menschen zu infizieren, vermögen aber auf der Hornhaut des Kaninchens nicht Fuß zu fassen.

Auf die anatomisch intakte Schleimhaut scheint das Virus nicht ausgeschieden zu werden. Jedenfalls konnten wir es niemals nachweisen, wenn nicht auch sichtbare Schleimhautveränderungen vorhanden waren. Auch der Speichel enthält, wie wir im experimentellen Teil berichteten, kein Virus, selbst wenn er von solchen Patienten entnommen wird, deren Gaumenschleimhaut mit Ulzerationen bedeckt ist.

Unsere bisherigen Erfahrungen über die Tröpfcheninfektion stützten sich im wesentlichen auf die Tuberkulose. Sicherlich liegen aber die Verhältnisse für eine Verbreitung der Krankheitskeime auf diesem Wege bei der Variola noch sehr viel günstiger. Während sich bei der Lungentuberkulose das Virus in den
Lungen entwickelt und nur zusammen mit dem ziemlich zähen Sputum nach außen gelangen kann, sind bei der Variola gerade die oberen Luftwege von den Trachea bis in die Mund- und Nasenschleimhaut erkrankt, und es ist wohl sehr wahrscheinlich, daß dadurch das Versprühen beträchtlich erleichtert wird. Auch die mutmaßliche Kleinheit des Variolaerregers dürfte nach den Untersuchungen der Flüggeschen Schule ein die Bildung feinster Tröpfchen begünstigender Faktor sein. Vor allem aber müssen wir die weit größere Empfänglichkeit des Menschen für das Variolavirus in Betracht ziehen: Gegen die Tuberkuloseinfektion besitzt der Mensch eine nicht unbeträchtliche natürliche Resistenz, und es werden daher meist größere Mengen von Tuberkelbazillen erforderlich sein, um eine Erkrankung zu erzeugen, während gegenüber dem Variolavirus der ungeimpfte Mensch von allen Lebewesen die weitaus geringste, wahrscheinlich schon durch ganz wenige Keime zu brechende Widerstandsfähigkeit besitzt. Die so häufig beobachtete Uebertragung der Pocken auch auf Personen, die mit dem Kranken nicht in direkte Berührung gekommen sind, findet also durch unsere Versuche eine ungezwungene Erklärung.

Die Annahme eines flüchtigen Virus, die neuerdings wieder von Jürgens vertreten wird, scheint uns daher nach unseren Ergebnissen überflüssig. Sie dürfte auch bei dem heutigen Stand der mikrobiologischen Forschung kaum mehr Daseinsberechtigung haben, wenn darunter nicht eben das auf dem Wege der Tröpfcheninfektion verbreitete Virus verstanden wird. Da wir uns Krankheitserreger nicht anders denn als korpuskuläre Elemente vorstellen können, so ist es undenkbar, daß sich solche aus einem flüssigen Medium, ohne gleichzeitigen Flüssigkeitstransport, in der Luft verbreiten sollten.

Die Urinuntersuchungen ergaben in Uebereinstimmung mit früheren Inokulationsversuchen ein negatives Resultat.

Wir kommen also zu dem Ergebnis, daß als Austrittspforte des Pockenvirus in erster Linie die typischen Effloreszenzen der Nasen-, Mund- und Luftröhrenschleimhaut, in den späteren Stadien der Erkrankung auch der Inhalt der geplatzten Hautpusteln in Frage kommen.

Als Eintritts pforten des Variolavirus kommen die Haut und die Schleimhäute des Respirationstraktus in Betracht. In den Lehrbüchern und monographischen Werken über die Pocken wird meist beiden Wegen eine Rolle zuerkannt. Ein eingehenderes Studium der älteren Literatur über die Variolation lehrt jedoch, daß die Aufnahme des Virus durch die Haut mehr als unwahrscheinlich ist. Nach den übereinstimmenden Schilderungen aller Autoren hat nämlich die Inokulation einen von der spontanen Variola in typischer Weise unterschiedenen Verlauf. Abgesehen davon, daß die Erkrankung bei der Variolation im allgemeinen leichter verläuft, ist vor allem die Inkubationszeit in ganz charakteristischer Weise bei beiden Formen der Erkrankung verschieden. Während bei der Variola die Inkubationszeit 13-14 Tage, die Zeit bis zum Ausbruch des Exanthems 16-17 Tage beträgt, treten bei der Variolation die ersten Krankheitserscheinungen schon am siebenten bis achten Tage auf, denen nach weiteren zwei Tagen das allgemeine Exanthem folgt. Der Unterschied der Inkubationszeiten beträgt also ungefähr eine Woche. Würde auch die natürliche Ansteckung ihren Weg durch die Haut nehmen, so wäre nicht einzusehen, warum nicht bei ihr der gleiche Krankheitsverlauf wie bei der Inokulation auftreten sollte. Die Methode der Variolation beweist also durch ihre Existenz, daß die Haut bei der natürlichen Pockeninfektion als Eintrittspforte nicht in Frage kom mt. Außerdem wäre wohl bei der ausgesprochenen Affinität des Pockenvirus zur Haut zu erwarten, daß bei kutaner Infektion hier auch die ersten Krankheitserscheinungen auftreten, wie wir dies bei der Inokulation ja tatsächlich beobachten.

Wir kommen daher zu dem SchluB, daß die Infektion ausschließlich durch die Schleimhaut der oberen Luftwege (Nase, Mund, Trachea) ihren Einzug nimmt. Ob es an diesen Stellen, wie L. Pf eiffer annahm, zur Bildung einer Protopustel kommt, haben wir bisher nicht feststellen können, aber, wie schon hervorgehoben wurde, sind unsere Beobachtungen an Frühfällen zu wenig 
zahlreich, um endgültige Schlüsse nach dieser Richtung zu ziehen.

Fassen wir unsere Anschauungen über den Infektionsmodus bei der Variola kurz zusammen, so gelangen wir zu folgender Darstellung:
Austrittspforten:
Schleimhautpustel, Hautpustel. Schleimhaut der oberen Luftwege.
Eintrittspforten:

Von der Schleimhaut wird das Virus direkt auf dem Wege der Tröpfcheninfejktion auf die gesunde Schleimhaut der oberen Luftwege übertragen. Dieser Weg kommt in den ersten Stadien der Erkrankung ausschließlich in Betracht und verliert seine Bedeutung mit der Abheilung der Schleimhateffloreszenzen, die nicht selten erst in der Rekonvaleszenz erfolgt.

Aus der Hautpustel gelangt das Virus durch Platzen der Epidermisschicht nach außen. Seine Weiterverbreitung erfolgt in erster Linie durch Einatmung des eingetrockneten und verstäubten Inhaltes der Pusteln. Auch indirekt kann die Krankheit durch den an Gegenständen angetrockneten Bläscheninhalt übertragen werden. Unmöglich ist es auch nicht, daß das Virus durch die mit Pustelinhalt infizierten Finger in den Mund gelangt und auf diesem Wege die Schleimhäute des Mundes oder Rachens infiziert. Eine direkte Uebertragung von der Hautpustel auf die Haut als Regel halten wir für ausgeschlossen. ${ }^{1}$ )

Vongroßer praktischer Bedeutung dürften unsere Ergebnisse bei Pockenrevaleszenten sein. Wenn auch unser Material in Anbetracht der gegenwärtig nur mit Schwierigkeiten durchzuführenden Tierversuche kein sehr umfangreiches ist, so konnten wir doch immerhin in 2 von 15 Fällen das Variolavirus noch wochenlang nach der Entfieberung in der Nasenschleimhaut nachweisen.

Wie häufig dies der Fall und wie lange sich das Virus beim klinisch Genesenen hält, werden weitere Untersuchungen erweisen müssen. Erst dann werden wir einen Vergleich mit anderen Infektionskrankheiten, dem Typhus, der Diphtherie u. a. ziehen können. Jedenfalls müssen wir aber mit der Möglichkeit rechnen, daß die Krankheit durch genesene Virusträger weiter verschleppt werden kann. Nach unseren Beobachtungen scheint es - obwohl auch das natürlich nur durch ausgedehntere Erfahrungen festgestellt werden kann -, daß das Virus sich nur dort hält, wo Ulzerationen auf der Nasenschleimhaut zurückbleiben. Eine genaue Untersuchung der Nasenschleimhaut mittels des Nasenspiegels sollte daher bei allen Pockenkranken, die zur Entlassung kommen, durchgeführt werden. Ob dies allerdings genügt, ob nicht verborgene Schleimhautläsionen der klinischen Beobachtung entgehen und dann doch noch die Kontrolle durch den Tierversuch notwendig machen, möchten wir noch nicht mit Sicherheit entscheiden. Jedenfalls müsse n wir aber schon heute die bisher ausschließlich ge übte Inspektion auf Hautschuppen und Borken als ungenügend bezeichnen.

$\mathrm{Ob}$ auch gesunde Virusträger bei der Uebertragung der Pocken eine Rolle spielen, möchten wir auf Grund unserer wenig zahlreichen Untersuchungen noch nicht entscheiden. Immerhin war das Resultat bei 20 aus der Umgebung Pockenkranker stammenden Personen negativ. Bei der zweifellos nachgewiesenen und auch von uns während dieser Epidemie wiederholt beobachteten Uebertragung der Pocken durch anscheinend gesunde Zwischenträger dürfte die Ansteckung wohl in Wirklichkeit meist durch ganz leichte, der Beobachtung entgangene Erkrankungen erfolgen. Wahrscheinlich kann aber die Krankheit auch durch das an Kleidung oder Gegenständen haftende Virus übertragen werden.

1) Natürlich soll damit das gelegentliche Vorkonmen einer richtigen Inokulation. von Variolavirus in die Haut nicht bezweifelt werden. Es kommt dann aber nicht zur Entwicklung des typischen Variolabildes, sondern es treten eben die klinischen Erscheinungen der Variolation auf. Ein solcher Fall wurde im Frühjahr 1917 beobachtet.
Nachschrift bei der Korrektur: Während der Drucklegung dieser Arbeit erschien eine Mitteilung von Pasohen über die Beteiligung der Schleimhaut der oberen Iuftwege bei Pocken. Pas chen konnte in Ausstrichen der Schleimhautpusteln die von ihm heschriebenen Körperchen immer nachweisen. (Hamburger Aerzte-Korrespondenz Nr. 20, 1917.) 